\title{
Tongue Lipoma: Report of 2 Cases and Review of Literature
}

\author{
Rasmané Béogo ${ }^{*}$, Toua Antoine Coulibaly¹, Ibraïma Traoré1, Valentin Konségré2, \\ Hèra Michel Kohoun ${ }^{1}$
}

\author{
${ }^{1}$ Department of Stomatology and Maxillofacial Surgery, CHU Souro Sanou, Bobo-Dioulasso, Burkina Faso \\ ${ }^{2}$ Department of Pathology, CHU Souro Sanou, Bobo-Dioulasso, Burkina Faso \\ Email: *rbeogo@yahoo.fr
}

How to cite this paper: Béogo, R., Coulibaly, T.A., Traoré, I., Konségré, V. and Kohoun, H.M. (2018) Tongue Lipoma: Report of 2 Cases and Review of Literature. Open Journal of Stomatology, 8, 271-276. https://doi.org/10.4236/ojst.2018.88025

Received: May 20, 2018

Accepted: August 27, 2018

Published: August 30, 2018

Copyright $\odot 2018$ by authors and Scientific Research Publishing Inc. This work is licensed under the Creative Commons Attribution International License (CC BY 4.0).

http://creativecommons.org/licenses/by/4.0/ (c) (i) Open Access

\begin{abstract}
Background: Tongue is an exceptional site of lipoma, a yet very common tumor. Aim: To improve awareness in tongue lipoma diagnosis and treatment approaches through a report of 2 cases and a review of literature. Case Report: A 57-year female patient presented with a large and long-standing mass of 10 years of duration of the base of the tongue, difficulties in feeding and speaking. Another patient of 33 years old presented with an asymptomatic swelling of the left side of the mobile tongue. The two patients had no remarkable medical history and their clinical examination was otherwise unremarkable. In all the two masses, macroscopic examination of the surgical specimen showed an elastic consistency and a yellowish cut surface. Microscopically, matures adipocytes in an abundant fibrous connective tissue were noted in one of the specimen and fibrolipoma was diagnosed. In the other one, matures adipocytes were noted and its patient was diagnosed as having lipoma. Discussion: Tongue lipoma diagnosis, clinically challenging, is easily suspected at macroscopic examination of surgical specimen of a tongue mass. Treatment should favor as possible as a non-mutilating approach given the benign character and the classical low propensity for recurrence of the tumor.
\end{abstract}

\section{Keywords}

Lipoma, Tongue Lipoma, Oral Lipoma

\section{Introduction}

Lipoma is a lesion composed of mature adipocytes, among the most common tumors of human body including the head and neck region however uncommon in the oral cavity [1] [2] [3]. Classically asymptomatic, tongue lipoma can however interfere with speech, mastication, swallow and breathing when it grows to 
large sizes [4] [5]. Surgical excision is the mainstay treatment with proven efficacy. Additionally it may enable to suspect lipoma, showing elastic consistency and yellowish cut surface at macroscopic examination. The low clinical suspicion index of tongue lipoma due to diversity of differential diagnoses which include benign tumors, malignant tumors, developmental or inflammatory lesions may however lead to challenging diagnosis and improper treatment [5]. This study aims to improve awareness in tongue lipoma diagnosis and treatment approaches through a report in 2 patients and a review of literature.

\section{Presentation of Cases}

Case 1: A 57-year old female presented with a large and long-standing mass of 10 years of duration of the base of the tongue (Figure 1). The patient complained of increasing difficulties in feeding and speaking however she alleged no asthenia or weight loss. At clinical examination the mass was multi nodular, covered by a normal mucosa and had a firm consistency. The patient's clinical examination was otherwise unremarkable, particularly palpation of the tongue noted no induration and that of the neck noted no lymphadenopathy. Under general anesthesia with nasal intubation, the mass was excised via incision of the mucosa followed by a blunt dissection of the muscles of the tongue. The extirpated lesion was well circumscribed, had an elastic consistency and a yellowish cut surface (Figure 2). Histological examination showed matures adipocytes in an abundant fibrous connective tissue (Figure 3 ) and the diagnosis of fibrolipoma was concluded. The patient's recovery was uneventful and at 4 years postoperatively no sign of recurrence was noted.

Case 2: A female patient of 33 years attended for a swelling of the left side of the mobile tongue (Figure 4). The overlying mucosa of this swelling was superficially ulcerated but the patient alleged neither lingual pain nor history of alcohol or tobacco addiction. The patient's physical examination was otherwise unremarkable, particularly the ulcer had no bleeding and palpation of the neck noted no lymphadenopathy. Under local anesthesia consisting in infiltration of lidocaine, a well encapsulated lesion of elastic consistency and yellowish color was removed. Matures adipocytes were noted at histological examination of the specimen and the patient was diagnosed as having lipoma. No sign of recurrence was noted at the patient's follow-up 3 years postoperatively.

\section{Discussion}

Oral cavity lipoma that of the tongue included is very rare, representing at more $5 \%$ of all the body localizations of the neoplasm [6] [7]. Lingual lipoma accounts for $0.3 \%$ of all tumors of the tongue and is unexpected given absence of adipose cells in the tongue [5]. This rarity and the variability of clinical presentations of tongue lipoma lead to low clinical suspicion index. A deep-seated tongue swelling imposes firstly for a fibroma, haemangioma, lymphangioma, abscess or thyroglossal duct cyst. A superficial mass of the tongue as in the case 1 of this 


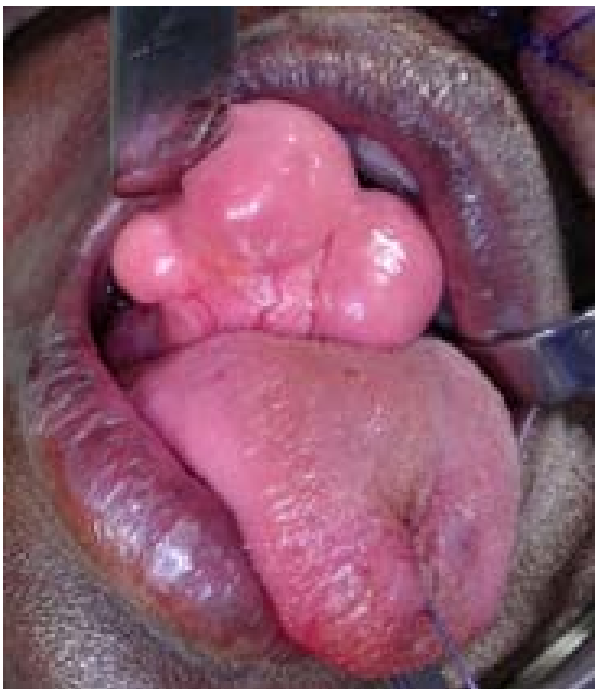

Figure 1. Tongue lipoma presenting as a large and long-standing mass of the base of the tongue.

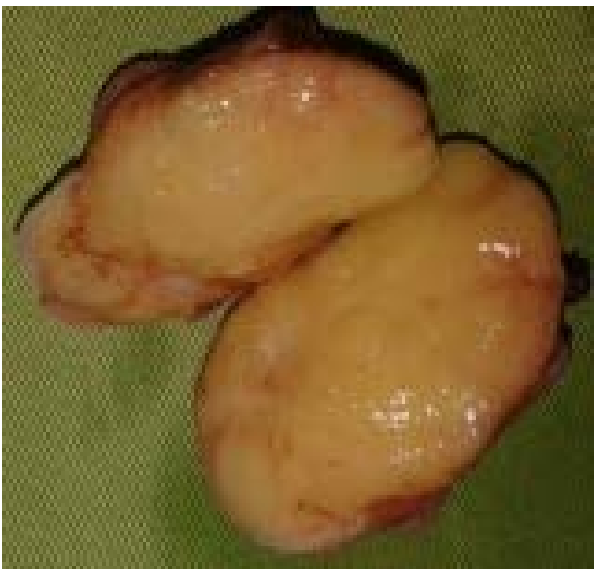

Figure 2. Cut surface of the surgical specimen of tongue lipoma showing a yellowish color.

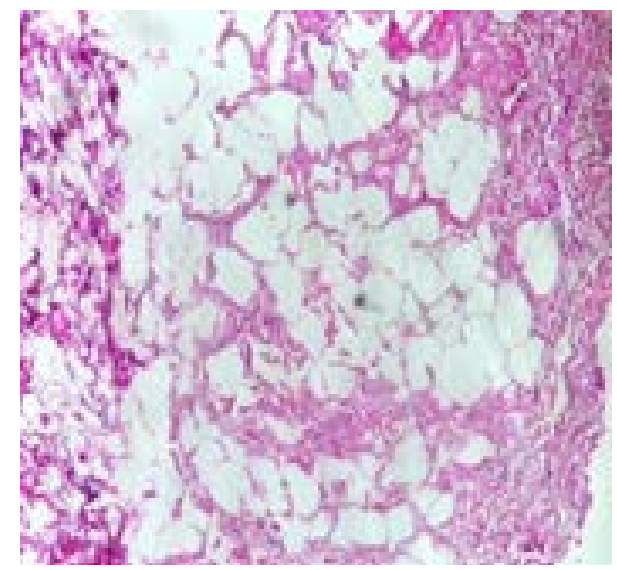

Figure 3. Histopathology of tongue fibrolipoma showing matures adipocytes in an abundant fibrous connective tissue. 


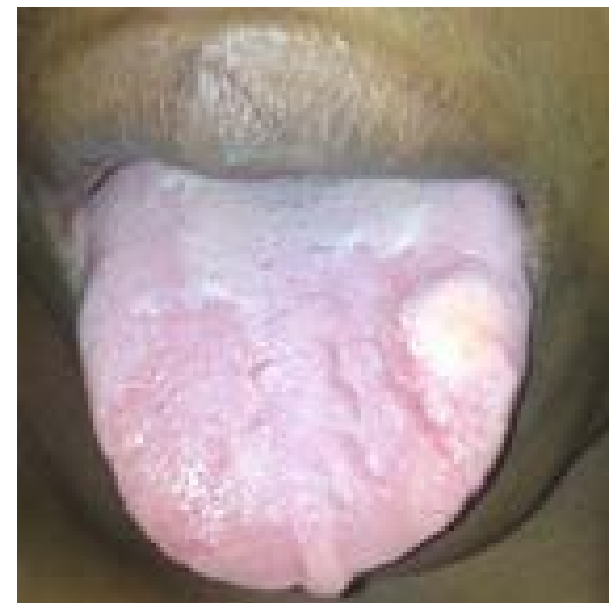

Figure 4. Tongue lipoma presenting as a superficially ulcerated swelling of the left side of the mobile tongue.

study may let think to ectopic thyroid tissue or a pleomorphic adenoma. When ulcerated as in the case 2 of this study, tongue lesion may impose for a carcinoma, particularly in individual with a risk factor such as alcohol or tobacco addiction. Clinical suspicion of lingual lipoma is easier at the ventral face of the tongue when thin mucosa enables perception of yellowish color and elastic consistency, consistent with the adipose tissue [8]. Medical imaging may help to suspect tongue lipoma. More than computed tomography (CT) scan which exposes to radiations and MRI not widely available, ultrasonography (US) should be used. CT scan shows a low mass density ranging from -60 to -120 Hounfield units consistent with the fatty tissue [9]. MRI, apart from suggesting lipoma diagnosis, shows accurately the tumor boundaries, vascularity and proximity to anatomic critical structures [9]. US shows lipoma as a lesion of round or elliptical shape classically hypoechogenic [10]. In tongue lipoma diagnosis approach, some authors use fine needle aspiration [11] [12] [13]. When contributive, this may help to differentiate clinically lipoma from conditions such as lymphangioma, heamangioma or abscess and even to affirm the diagnosis of lipoma by cytological examination. Other authors proceed by lesion incisional biopsy [4]. As in this study, diagnosis of lipoma may be suggested not before the surgical removal of an apparently benign tongue mass which shows elastic consistency and yellowish cut surface at macroscopic examination. Adult fat tissue cells at microscopic examination provides definitive diagnosis of lipoma and enables to exclude liposarcoma [14]. On the basis of the properties of these cells and those of their surrounding matrix, lipomas are classified as simple or classical lipoma and lipoma variants of which fibrolipoma. Classical lipoma and fibrolipoma noted in this study are reported as the more prevalent histological subtypes in some wide series [11] [15]. Surgical excision is the mainstay treatment of lipoma whatever the histological subtype with proven efficacy. Recurrences are exceptional in classical lipoma but can reach up to $60 \%$ of frequency in infiltrating or intra 
muscular lipoma, classically due to inadequate excision [8] [11] [15] [16]. Any recurrence should raise suspicion for liposarcoma [13]. Apart from surgery, intralesional injection of steroids and liposuction are reported in treatment modalities of lipoma [17]. Triamcinolone acetonide is the steroid classically used, at volume varying from 1 to $3 \mathrm{ml}$ depending on the tumor size, at monthly injections [17]. Steroids mechanism of action in lipoma is atrophy of the adipose tissue, achieved at best when the tumor size is less than $2.5 \mathrm{~cm}$ [17]. Liposuction is valuable whatever the tumor size [17]. It enables aditionally to avoid surgical scar.

\section{Conclusion}

Tongue lipoma diagnosis, clinically challenging, is easily suspected at macroscopic examination of surgical specimen of a mass of the tongue. Treatment should favor as possible as a non-mutilating approach given the benign character and the classical low propensity for recurrence of the tumor.

\section{Conflicts of Interest}

None declared.

\section{Compliance with Ethical Standards}

Informed consent was obtained from the patients.

\section{References}

[1] Taira, Y., Yasukawa, K., Yamamori, I. and Iino, M. (2012) Oral Lipoma Extending Superiorly from Mandibular Gingivobuccal Fold to Gingiva: A Case Report and Analysis of 207 Patients with Oral Lipoma in Japan. Odontology, 100, 104-108. https://doi.org/10.1007/s10266-011-0027-0

[2] Bandéca, M.C., de Pádua, J.M., Nadalin, M.R., Ozório, J.E., Silva-Sousa, Y.T. and Da Cruz Perez, D.E. (2007) Oral Soft Tissues Lipomas: A Case Series. Journal of the Canadian Dental Association, 73, 431-434.

[3] Hoseini, A.T., Razavi, S.M. and Khabazian, A. (2010) Lipoma in Oral Mucosa: Two Case Reports. Dental Research Journal, 7, 41-43.

[4] Chidzonga, M.M., Mahomva, L. and Marimo, C. (2006) Gigantic Tongue Lipoma: A Case Report. Medicina Oral Patologia Oral y CirugiaBucal, 11, 437-439.

[5] Chandak, S., Pandilwar, P.K., Chandak, T. and Mundhada, R. (2012) Huge Lipoma of Tongue. Contemporary Clinical Dentistry, 3, 507-509. https://doi.org/10.4103/0976-237X.107457

[6] Colella, G., Biondi, P., Caltabiano, R., Vecchio, G.M., Amico, P. and Magro, G. (2009) Giant Intramuscular Lipoma of the Tongue: A Case Report and Literature Review. Cases Journal. https://doi.org/10.4076/1757-1626-2-7906

[7] Manjunatha, B.S., Pateel, G.S. and Shah, V. (2010) Oral Fibrolipoma-A Rare Histological Entity: Report of 3 Cases and Review of Literature. Journal of Dentistry, 7, 226-231.

[8] Magadum, D., Appasab, S., Jiwanasha, M.A. and Manish, S.A. (2013) Classic Tongue Lipoma: A Common Tumour at a Rare Site. BMJ Case Reports. 
https://doi.org/10.1136/bcr-2012-007987

[9] Cappabianca, S., Barberi, A., Walter, D.V., Antonio, L., Gian, P.T. and Colella, G. (2003) Giant Infiltrating Lipoma of the Face: CT and MR Imaging Findings. American Journal of Neuroradiology, 24, 283-286.

[10] Shane, M.T. and Ivan, C. (2014) Intramuscular Lipoma: A Review of the Literature. Orthopedic Reviews, 6, 5618.

[11] Egido-Moreno, S., Lozano-Porras, A.B., Mishra, S., Allegue-Allegue, M., Marí-Roig, A. and López-López, J. (2016) Intraoral Lipomas: Review of Literature and Report of Two Clinical Cases. Journal of Clinical and Experimental Dentistry, 8, e597-e603. https://doi.org/10.4317/jced.52926

[12] Jose, L.D.C.P.V., Jose, L.C.C. and Elena.G.G. (2004) Ulcera crónica lingual inducida por lipoma de la cavidad oral. Casoclinico. Medicina Oral Patologia Oral y Cirugia Bucal, 9, 163-167.

[13] Rikhotso, R.E., Mhlanga, G. and Bobat, M. (2017) Giant Lipoma of the Head and Neck Region: Case Report and Review of the Literature. Open Journal of Stomatology, 7, 469-474. https://doi.org/10.4236/ojst.2017.711042

[14] Piattelli, A., Rubies, C., Fioroni, M. and Steches, G. (2000) Spindle-Cell Lipoma of the Cheek: A Case Report. Oral Oncology, 36, 495-496. https://doi.org/10.1016/S1368-8375(00)00035-X

[15] Lu Shu-Lai, Zheng, J.J., Wu, H., Li, T., Dong, G., Yun-Long, W. and Pi-Shan, Y. (2016) Tongue Lipoma in an Older Male: A Case Report and Literature Review of Patients with Tongue Lipoma Reported in China. Oncology Letters, 11, 419-422. https://doi.org/10.3892/ol.2015.3865

[16] Roles, D.M. (1995) Lipoma of the Tongue. British Journal of Oral and Maxillofacial Surgery, 33, 196-197. https://doi.org/10.1016/0266-4356(95)90307-0

[17] Kumar, L.K., Kurien, N.M., Raghavan, V.B., Menon, P.V. and Khalam, S.A. (2014) Intraoral Lipoma: A Case Report. Case Reports in Medicine.

https://doi.org/10.1155/2014/480130 